\title{
DOCENCIA UNIVERSITARIA E INVESTIGACIÓN: ¿COMPLEMENTO O ESQUIZOFRENIA?
}

\section{UNIVERSITY TEACHING AND RESEARCH: COMPLEMENT OR SCHIZOPHRENIA?}

\author{
AUTORES \\ José L. Yela: Area de Biología Animal, Facultad de Ciencias Experimentales, \\ Universidad Pablo de Olavide, Ctra. de Utrera, km 1, 41013 Sevilla. Dirección actual: \\ Area de Biología Animal, Facultad de Ciencias del Medio Ambiente, Universidad de \\ Castilla-La Mancha, Real Fábrica de Armas, Avda. Carlos III s. n., 45004 Toledo. \\ http://www.upo.es/depa/webdex/yela.html \\ jlyelgar@dex.upo.es \\ jlyela@amb-to.uclm.es
}

\section{CURRÍCULUM VITAE}

Profesor titular de Zoología y Conservación Biológica, Facultad de Ciencias del Medio Ambiente, Universidad de Castilla-La Mancha.

\section{RESUMEN}

Soy consciente de que los títulos del artículo y de este mismo párrafo pueden parecer pretenciosos (el del artículo, además, ciertamente provocador). Opiniones mucho más autorizadas que la mía, que no deja de ser la de un modesto observador de los hechos, han sido publicadas repetidamente, algunas documentadas con profusión de datos. Con estas líneas, aclaro, sólo pretendo contribuir al debate con una reflexión más, hecha en términos elementales por un docente de a pie. Naturalmente, mi opinión es sólo mía, y por lo tanto parcial por definición. Contribuya quien lo desee 
a complementarla; rebátaseme todo lo que sea necesario. Se supone que todos saldremos ganando.

\title{
PALABRAS CLAVE
}

Docencia - Investigación - Esquizofrenia

\begin{abstract}
I am aware that the title of the article and this paragraph may seem pretentious (the article also certainly provocative). Reviews more authoritative than mine, which continues to be that of a modest observer of events, have been published repeatedly, some profusely documented data. With these lines, I clarify, I intend to contribute to the debate only a reflection, in terms of elements made by a teacher on the street. Of course, my opinion is mine alone, and therefore by definition partial. Help those who wish to supplement it; rebátaseme whatever is necessary. It is assumed that Everybody.
\end{abstract}

\section{KEY WORDS}

Teaching - Research - Schizophrenia

\section{ÍNDICE}

1. La Universidad en la sociedad: papeles, responsabilidades y conflictos

2. Naturaleza de la labor del profesorado universitario y criterios de evaluación de su actividad: un toma y daca claramente asimétrico

3. Obligaciones del personal docente: de la teoría a la práctica, o la desconcertante esquizofrenia 


\section{Agradecimiento \\ 5. Bibliografía}

\section{La Universidad en la sociedad: papeles, responsabilidades y conflictos}

Soy consciente de que los títulos del artículo y de este mismo párrafo pueden parecer pretenciosos (el del artículo, además, ciertamente provocador). Opiniones mucho más autorizadas que la mía, que no deja de ser la de un modesto observador de los hechos, han sido publicadas repetidamente, algunas documentadas con profusión de datos. Con estas líneas, aclaro, sólo pretendo contribuir al debate con una reflexión más, hecha en términos elementales por un docente "de a pie". Naturalmente, mi opinión es sólo mía, y por lo tanto parcial por definición. Contribuya quien lo desee a complementarla; rebátaseme todo lo que sea necesario. Se supone que todos saldremos ganando.

Una cuestión previa que me veo en la necesidad de abordar, aunque sea muy por encima, es la que se refiere al modelo de Universidad que se precisa hoy día para satisfacer las demandas sociales. Antiguamente, a la Universidad acudían fundamentalmente aquellos que necesitaban una instrucción superior (o simplemente un título) que les capacitase para ejercer una profesión cualificada. Hoy en día cursan estudios superiores muchas personas a las que no podrá absorber el mercado laboral, que lo hacen más bien para adquirir un bagaje cultural. Surge la pregunta: ¿debemos concebir una Universidad que prepare buenos profesionales o una Universidad que se preocupe de la formación intelectual y moral del alumnado? (véase C. Yela, en prensa). A muchos puede parecerles una pregunta banal, entre 
ellos a quienes por diversas circunstancias deben estar tan pendientes de su propia situación personal que no tienen tiempo para ocuparse de las cuestiones de interés común. A mí, modestamente, me parece una pregunta capital. Incluso creo que muchos de los malentendidos y posturas encontradas entre el personal universitario se deben a que, en el fondo, concebimos la Universidad de diferentes maneras y partimos, pues, de premisas diferentes. Esto es debido en parte a que la dinámica social es vertiginosa y se asimila diferencialmente por unos y otros, en parte a que apenas debatimos sobre estos asuntos y en parte a que muchos, por unas $\mathrm{u}$ otras razones, estamos sujetos a un cierto grado de dejadez e inoperancia.

Ante todo, aclararé que personalmente abogo por un modelo que participe, a partes iguales, de ambas facetas de la formación. O mejor dicho, de las tres facetas de que debe constar, la académica (como conjunto de conocimientos teóricos), la técnica (como conjunto de métodos y herramientas para solucionar los problemas inherentes al ejercicio de la profesión) y la intelectual y moral (como conjunto de valores que fomenten la capacidad crítica, la tolerancia, el trabajo en equipo y la proyección social de los conocimientos, o en otras palabras, las cualidades para ser capaces de llevar a la práctica el método científico tanto en un contexto investigador como en un contexto social). Al preparar una clase creo que debe pensarse en la utilidad que el contenido tendrá para el alumno tanto culturalmente como técnicamente, en su ulterior vida profesional, y tanto científicamente como humanamente, sea cual sea su dedicación posterior.

Aunque la realidad social española haya cambiado tanto durante el último siglo, creo que el pensamiento de José Ortega y Gasset sigue plenamente vigente en muchos aspectos, y con él, reconozco tres funciones básicas de la Universidad (véase Ortega y Gasset, 1930): 1) la investigación y la docencia, 2) la enseñanza de las profesiones y 3) la transmisión de la cultura. Que viene a ser, con otras palabras, lo mismo que he expuesto más arriba. La docencia cubre la faceta de adiestramiento intelectual, 
cultural y moral; la enseñanza de las profesiones, la faceta de adiestramiento técnico. Por otro lado, del mismo juicio de Ortega y Gasset se desprende el papel clave de la Universidad en las sociedades llamadas "avanzadas", puesto que de ella depende, en gran medida, el progreso científico y técnico (en España, junto con otras instituciones públicas de investigación como el CSIC, el CIEMAT, el INIA, etc.), la formación de los futuros profesionales cualificados y la divulgación de los conocimientos científicos al resto del tejido social. Debido a su dimensión social, la Universidad tiene, pues, un papel que trasciende su propio ámbito académico (http://www.crue.upm.es, capítulo II). De ahí la gran responsabilidad del profesorado universitario.

En la introducción de otro artículo (Yela, en prensa a) he revisado, sobre la base de mi propia experiencia, algunos de los conflictos que aquejan al sistema universitario español actual. En particular, he puesto de relieve algunos de los vicios del personal universitario, que no favorecen precisamente la consecución satisfactoria de los fines enumerados más arriba. Vicios, dicho sea de paso, seculares (Ramón y Cajal, 1919), que no tienen relación directa con la edad ni con la situación geográfica de las Universidades, y que en mi modesta opinión derivan fundamentalmente de la condición funcionarial mal entendida, pero ampliamente asumida, de una parte importante de quienes en algún momento consiguieron "su" plaza vitalicia (en la definición, jocosa y algo exagerada, que le he dado a esta condición en el mencionado artículo, "perverso eje central del sistema I+D+I español"). Algunos de esos vicios tienen consecuencias que no dudo en calificar de terribles, por estar en el mismo cimiento de la educación de un amplio sector de nuestra juventud. Una parte notable de los profesores universitarios españoles, o bien no parece ser muy consciente de la trascendencia social de su labor, o bien actúa como si no lo fuera, que a efectos prácticos es lo mismo, y cumple sus funciones (o algunas de ellas) de manera harto rutinaria, transmitiendo cierta dejadez y monotonía al alumnado, o inhibiéndose cuando hay que adoptar posturas de firmeza ante determinadas situaciones. A todos 
nos interesa, al menos a largo plazo, corregir las desviaciones. Por ello, algunos "perdemos el tiempo" reflexionando sobre estas cuestiones. Y no es que nuestra intención sea importunar al remover aguas fangosas; es que no hay manera de solucionar los problemas si no se definen claramente y si no se pregunta uno el porqué.

En este artículo intento adoptar una perspectiva diferente que en el anterior. Es decir, trato de ponerme en el lugar del profesor que, a pesar de las dificultades que todos conocemos, intenta cumplir con decoro su papel y se pregunta: ¿qué puedo hacer, desde un puesto vitalicio, en una institución como la Universidad española, para contribuir a satisfacer los objetivos que debe tener una Universidad moderna? ¿Hacia dónde dirigir mis esfuerzos, hacia la formación integral, es decir, comprensiva (en lo profesional y en lo intelectual y moral), actualizada, rigurosa y excelente, de los alumnos, hacia mi propia tarea investigadora o hacia la divulgación del conocimiento? O dicho de otra forma: ¿cómo observar la importante función social de mi cargo, y a la vez cumplir decorosamente con mis obligaciones docentes primarias y con mis tareas investigadoras? Cuestión compleja, sin duda. Conste, me interesa mucho resaltarlo y por eso insisto de nuevo, que no es mi intención dar lecciones a nadie; sería de una petulancia colosal por mi parte. No intento más que colaborar, al margen de los cauces habituales, la mayor parte ciertamente desvirtuados, a provocar un debate que muchos estimamos capital y urgente, y que los intereses corporativos ( $\mathrm{y}$, todo hay que decirlo, egoístas y miopes) de sectores poderosos de las autoridades académicas y del profesorado funcionario intentan acallar sistemáticamente por acción u omisión, con paños calientes y palabras de aparente concordia. O directamente "por las bravas".

El tejido social español identifica la Universidad casi exclusivamente con la docencia y la enseñanza de las profesiones, y algo menos con la transmisión de la cultura. La investigación apenas es tenida en cuenta por el ciudadano medio como un factor 
clave de la vida universitaria. El profesor es considerado poco más que un maestro. Las razones históricas que explican este hecho son fuertes (y el futuro es incierto al haber quedado la Universidad adscrita recientemente al Ministerio de Educación, Cultura y Deporte, mientras que todos los demás organismos relacionados con la investigación han pasado a formar parte del nuevo Ministerio de Ciencia y Tecnología). En parte por ello, muchos padres sólo perciben la Universidad como el lugar donde sus hijos obtendrán un título que les capacitará para desarrollar una profesión supuestamente bien considerada, o que al menos les dará la oportunidad de tener una formación relativamente sólida. En general, no se detienen a pensar que la calidad de la enseñanza que sus hijos reciban dependerá, al menos en su parte técnica, de la investigación que realicen sus profesores. Habremos de preguntarnos, y de hecho muchos nos lo preguntamos, si no tenemos parte de culpa nosotros, los universitarios, que no hemos aprendido a explicar suficientemente bien al ciudadano el papel crucial que juega la investigación en la vida universitaria (y, por supuesto, en el progreso, entendido "progreso" en su sentido "adaptativo", como aumento de seguridad y bienestar ante situaciones imprevistas, con el consecuente aumento de eficacia biológica; Yela, 2000). Quizá es que estamos tan ocupados con otras tareas que, materialmente, no nos queda tiempo de explicarlo...

\section{Naturaleza de la labor del profesorado universitario y criterios de evaluación de su actividad: un toma y daca claramente asimétrico}

Entre nosotros, los universitarios, parece que hay un cierto consenso en que la investigación debe ser consustancial a la Universidad, y que una Universidad sin un mínimo de investigación de calidad no es digna de llamarse tal. Existe también un cierto consenso en que la pertinencia, la eventual aplicabilidad y la excelencia de los méritos investigadores deben ser convenientemente valoradas (aunque la idoneidad de los métodos utilizados para la evaluación sea puesta en tela de juicio por algunos, desde diferentes ópticas; pero ese es otro debate). Hasta aquí bien. Sin embargo, 
muchos defienden que el único criterio para la evaluación del profesorado debe ser la calidad de su investigación, medida como número de artículos publicados en revistas recogidas en el índice de citas científicas (el famoso SCI) (y, en algunos casos, como número de patentes). Estando de acuerdo en que el criterio es válido para la evaluación de la calidad investigadora (como opina Carrascal, 1997), no lo estoy en que deba ser el único criterio para la evaluación de la actividad de un profesor universitario (en lo que coincido en parte con Camí, 1997). ¿Cómo, pues, podrían satisfacerse en tal caso con garantías los objetivos de la docencia, de la enseñanza de las profesiones y de la transmisión de la cultura al tejido social? Si fuera el único criterio, ¿no estaríamos perdiendo una parte importante de nuestra razón de ser? ¿Qué sentido tendría, en este caso, el CSIC?

Defiendo sin ambages que todo profesor universitario debe ser un buen investigador, puesto que un buen investigador está necesariamente al día de los avances que se producen en su campo y, al menos en principio, debe estar más o menos entrenado en la crítica y en la duda metódica, inherentes al método científico. Sin embargo, a diferencia de muchos colegas, puesta de manifiesto básicamente en la lista de distribución de la Asociación para el Avance de la Ciencia y la Tecnología de España, AACTE (véase http://www.aacte.net), sí pongo en seria duda que todo buen investigador sea necesariamente un buen docente universitario, particularmente en los aspectos menos técnicos (el caso opuesto ni siquiera lo planteo, dada su obviedad). Es más, una parte no despreciable de los buenos investigadores que personalmente conozco en la Universidad no son docentes brillantes ni comprometidos, unos confusos al explicarse, otros más o menos despreocupados de la formación de los alumnos (preocupados, eso sí, de su investigación). Esto, creo, es un hecho, no sólo una apreciación personal, como en mi modesta opinión lo confirman, entre otras cosas: 1) el descontento generalizado y el "pasotismo" del alumnado, que se siente en general escasamente motivado por lo que se le transmite; y 2) la mentalidad con que muchos alumnos se enfrentan a los estudios (a aprobar, y 
punto) y con la que salen de la Licenciatura o Ingeniería (en general, con escasa iniciativa y flexibilidad y con unas miras bastante reducidas). La principal dificultad de éstos a lo largo de la carrera es la que deriva de la frustración personal de comprobar la enorme distancia que separa lo que esperan de lo que reciben. Esperan recibir una información sugerente, que les motive, que les haga pensar y que sea innovadora, y lo que en general se encuentran es una información hasta cierto punto repetitiva de lo que pone en los libros de texto, que les motiva poco, que les enseña a pensar poco por sí mismos y les fomenta poco el espíritu crítico, y que en el caso de algunas asignaturas tiene poco de novedad.

Se puede argüir que en toda muestra hay una variabilidad, y que esa variabilidad inherente puede explicar que un cierto porcentaje del alumnado pase con escasa ilusión y miras reducidas por la Universidad. Aun admitiéndolo, resulta que ese porcentaje es tan alto que no creo que se pueda explicar sólo como variabilidad intrínseca. Creo que hay otras razones, y lo creo desde que yo mismo era alumno. Creo que, en general, en clase aprenden poco más que rutina; no les damos mucho más. Obviamente, esto es muy variable entre profesores, Areas, Departamentos, Facultades y Universidades; pero, insisto, hablo en términos generales. Su escasa motivación respecto a la enseñanza creo que tiene su origen en el comportamiento repetitivo, gris y aburrido de nosotros, los docentes, y en el abuso por nuestra parte de la lección magistral unidireccional. Estamos preocupados de otras cosas que tienen que ver más con nuestros intereses personales (es decir, con nuestra promoción). Como consecuencia, la atención que prestamos a la faceta docente es, en general, relativamente reducida. No solemos enfrentar al alumnado a la evaluación de contrastes de hipótesis alternativas, que es una tarea intelectual algo menos sencilla que el simple aprendizaje de un enunciado, ni solemos fomentar mecanismos participativos en clase. 
Creo que es una pena que los alumnos estén tan escasamente entrenados en estas dinámicas, que contribuyen de manera muy efectiva a enseñarles a decidir por sí mismos y a que comparen diferentes puntos de vista. En definitiva, a fomentar su espíritu crítico, que es esencial en ciencia, y que tanta falta hace en nuestra sociedad en general; no hay más que ver los gallineros en que se convierten muchos programas de debate por televisión, o la reducida capacidad de asimilación de las posturas alternativas puesta de manifiesto por la mayoría de nuestros políticos, demasiado pendientes, en mi opinión, de contentar al gremio correspondiente. Normalmente, a los alumnos sólo se les enseña las más aceptadas de las posibles interpretaciones que pueden tener los hechos explicados, sin entrar a analizar en detalle causas y razones. No es que ello no sea necesario; es que creo que es mucho más enriquecedor enseñarles además a pensar cómo resolver problemas en función de diferentes respuestas alternativas. Algunos de entre los que sí dedican atención suficiente a la docencia estarán pensando que "cómo vamos a hacerlo si la masificación es tan enorme"...

Evidentemente, la masificación es un grave inconveniente, que enlaza directamente con la queja reiterada de los vicerrectores de profesorado: los paupérrimos presupuestos que suelen manejarse para la contratación digna de un número suficiente de docentes de calidad contrastada que puedan hacerse cargo de una formación integral y excelente de tantos alumnos como se matriculan. Pero, mientras el problema se resuelve a los niveles a los que tiene que resolverse, los docentes no nos podemos cruzar de brazos. A pesar de que, en general, estemos escasamente motivados porque la situación de altísima competitividad, masificación, sueldo escaso (o sencillamente ridículo), exceso de obligaciones, jerarquización exagerada y concomitante sumisión, etc., nos atosigue, y una de las consecuencias de ello es que tendamos a despreocuparnos de ser innovadores y creativos en clase, debemos estar muy alerta para no transmitir esa desmotivación al alumnado. Esto es fundamental, en el beneficio de ellos y en el nuestro propio. Si algo he aprendido en el tiempo que 
llevo en la Universidad es que no hay nada más gratificante para un profesor como un alumnado entusiasmado. Transcribo algunas frases de mi anterior artículo (Yela, en prensa a):

"... si uno se compromete con la tarea [de la docencia], puede experimentar uno de los procesos más enriquecedores que imaginarse cabe. La razón es bien sencilla: a medida que uno da más de sí, si el colectivo es receptivo y tiene interés le va devolviendo a uno lo que uno entrega multiplicado por varios órdenes de magnitud (y no olvidemos que la receptividad de la audiencia depende en buena medida de la habilidad para despertarla del que habla). A medida que durante estos dos primeros años en la Universidad les he tenido que ir explicando a mis alumnos, dentro y sobre todo fuera de clase, más y más cuestiones relacionadas con la diversidad de la vida animal, con su evolución, organización y funcionamiento o con las técnicas de muestreo, estudio e identificación de los animales, más he tenido que profundizar yo mismo para intentar resolver sus preguntas y más he aprendido de sus constantes observaciones. Cuesta mucho preparar las clases, si uno trata de estar al día y de ser mínimamente original y didáctico; pero cuanto más interés y emoción pone uno en prepararlas y darlas, más interés y emoción se despierta en los alumnos. Alumnos interesados y emocionados con la asignatura son un tesoro de valor incalculable, una fuente inagotable de estímulo intelectual. Puedo dar fe de ello. Son el núcleo de lo que podría ser, si este país estuviera realmente a la altura de las circunstancias en materia educativa, un futuro grupo docente e investigador vocacional; son, en todo caso, excelentes profesionales en potencia."

Desde mi punto de vista, conseguir "enganchar" al alumnado es fundamental, y como digo en otro lugar (Yela, en prensa b), sólo consiste en "...[trasmitir] nuestro entusiasmo a nuestros estudiantes, [haciéndoles] nuestros aliados y no nuestros enemigos (como tantas veces sucede)." 
Otros pensarán, "ya está aquí el idealista inexperto, ya nos lo contarás cuando lleves 10 años en la docencia universitaria". De hecho, este comentario lo he escuchado en múltiples ocasiones, en particular durante los dos años pasados. Confieso que me revuelve las entrañas. ¿No esconde tras de sí un olvido más o menos interesado de que el objetivo fundamental es la formación integral y puesta al día de los alumnos, al margen del esfuerzo que eso pueda suponerle al profesor? ¿No refleja el lamento del derrotado? Respondo a ese comentario, para situar la cuestión en contexto, que no soy un advenedizo; aparte de 2 años de asociado en la Universidad, he estado 8 años de postdoctoral en el CSIC, en el NERC británico y en el INIA, y aunque obviamente no es lo mismo porque allí los únicos estudiantes son de tercer ciclo, siempre he defendido la misma idea; es más, cada día me asiento más sólidamente en ella. Y respondo que he vivido en el ambiente universitario desde que nací, por razones familiares, o sea que no me resulta desconocido ni mucho menos. Y que no soy el único que piensa así; afortunadamente, hay colegas con larga experiencia universitaria que están en la misma línea, cuyo ejemplo no hace sino reafirmarme en mis posturas.

Las actitudes conformistas, aunque en parte comprensibles, no conducen a nada si tomamos mínimamente en consideración el bien común, y no solamente nuestra propia situación personal (o del grupito que nos da cobertura, supongo que se me entiende). Si acaso, a lo que contribuyen es a perpetuar la misma rutina y los mismos defectos de siempre. Otra cosa es que, lamentablemente, pienso yo, haya tanto conformista entre nosotros. Pero de lo que se trata no es (Yela, en prensa b) "...de "dorar la píldora" a nuestros administradores para que nos favorezcan en lo personal, como se interpreta en (tantas) ocasiones; se trata de hacerles comprender cuestiones que a veces no les resulta grato oir, por distintos motivos. Se trata de insistir en remodelar ciertas estructuras de base (en la Universidad, en el CSIC, en el Ministerio) si éstas no funcionan adecuadamente, y no de amoldarse a ellas, como solemos hacer 
(iy luego nos quejamos!). Habrá que insistir en ello, con la actitud más correcta y las mejores palabras. Con arte, si es necesario. Y habrá que hacerlo ya (insisto: en esta línea trabaja la AACTE, http:/ / www.aacte.net)."

Analicemos con un poco más de detalle las razones de la desmotivación y el bajísimo nivel de compromiso de tantos docentes universitarios, como base de la del alumnado. Obviamente, no me refiero al "compromiso" con los intereses propios o del gremio correspondiente, sea éste Area, Facultad o Departamento, sino con los intereses generales de la Universidad como institución al servicio del alumno, del ciudadano. Hay que recordar esto, porque ambos factores se confunden con inusitada frecuencia (¿cuántas veces nos presentamos a determinados cargos académicos para obtener, en primer lugar, un beneficio propio, lo que implica tener que ajustarse a ciertas exigencias de quien manda, y consecuentemente tener la boca al menos parcialmente sellada?).

Las razones de la desmotivación han quedado en parte bosquejadas más arriba: masificación (como número exagerado de profesores en condiciones precarias "en la lista de espera" para que salga "su" plaza, lo que genera toda clase de movimientos subterráneos y favorece los servilismos más insospechados y escandalosos, y como relación profesor / alumnos bajísima), escasez de incentivos económicos, exceso de obligaciones (básicamente, cargas docentes exageradas y presión acuciante por publicar) y, en no pocas ocasiones, sometimiento a las decisiones impuestas por quienes hacen del funcionariado poco menos que un reinecillo de Taifas. Nótese que las dos primeras causas son, en definitiva, económicas; en algún punto, la gestión de los recursos destinados a la Universidad hace aguas. O bien no se proporcionan suficientes fondos por parte del Gobierno (o Gobiernos autonómicos) en relación a la demanda social actual (lo que no implica que la demanda social esté suficientemente justificada, esa es otra cuestión), o bien parte de esos fondos se divierte hacia objetivos que podrían ser secundarios (por ejemplo, infraestructuras de utilidad al 
menos cuestionable; véanse cifras en http://www.crue.upm.es, capítulo V), o bien ambas cosas a la vez. No me voy a pronunciar sobre estas posibilidades porque no tengo datos de primera mano suficientemente contrastables. Tampoco sobre la interpretación funcionarial, gremial y monolítica de la actividad universitaria, comentada como digo en otro artículo (Yela, en prensa a). A partir de aquí me voy a centrar sólo en lo referente al exceso de obligaciones del personal docente (al que, en definitiva, subyace también una componente financiera importante).

\section{Obligaciones del personal docente: de la teoría a la práctica, o la desconcertante esquizofrenia}

Satisfacer adecuadamente los objetivos de la Universidad enumerados al principio exige al profesor universitario ser a un tiempo docente (en su triple vertiente académica, técnica e intelectual), investigador y divulgador. Es obvio que no todos estamos preparados ni tenemos las mismas habilidades para cualquiera de esas facetas; unos destacan más en unas y otros en otras. Pero, en buena lógica, sí debería exigírsenos que cumpliéramos unos mínimos. Sin embargo, y he aquí la cuestión clave, ¿para qué se nos contrata cuando venimos a una Universidad? Es decir, ¿por qué actividad se nos paga nuestro sueldo regular? Y sin embargo, ¿qué se nos exige a la hora de promocionar? Pensemos sobre ello...

... e inmediatamente nos daremos cuenta de que algo no cuadra, algo que puede estar en la misma base de la desmotivación del personal docente. Desde hace más o menos dos décadas, es decir, a raíz de la entrada en vigor de la LRU, el sistema universitario español está inmerso en una abierta contradicción (la "esquizofrenia" del título), con la que convivimos en un equilibrio inestable. Esta contradicción, en vez de amortiguarse como hubiera sido deseable, se agravó más a raíz de la entrada en funcionamiento de la Agencia Nacional de Evaluación y Prospectiva (ANEP), hacia 
el paso de la década del 80 a la del 90. Nos acostumbramos a ella y llegamos a no percibirla (jcomo tantas otras cosas!), pero no por ello deja de estar ahí presente. En términos llanos, consiste en que a los profesores se nos contrata (es decir, se nos paga) exclusivamente para dar clases, en función de las necesidades docentes. Esa actividad, y no otra, es la que nos permite (sobre)vivir. Toda cantidad que deriva de actividades investigadoras es complementaria, y hay muchos que pasan perfectamente sin ella. Pero, paradójicamente, nuestra promoción se basa sobre todo, y cada vez más, en nuestra producción investigadora (al menos, en el caso de las áreas de Ciencias). O sea, nuestra promoción se basa en una actividad que desde el punto de vista de quien nos ha contratado ni siquiera es tenida en cuenta y por cuya ausencia, obviamente, no se van a pedir responsabilidades; es simplemente un epifenómeno, podríamos decir.

¿Es o no una situación equívoca? ¿Cómo es posible que, a la hora de los contratos, no conste explícitamente la actividad investigadora a realizar como número de horas a invertir en ella? ¿Es esto, o no, prueba (como hay otras, puestas de manifiesto en el mismo "informe Bricall") de que algunas autoridades universitarias no acaban de entender bien el papel clave de la investigación, por más que a la hora de resaltar los logros del personal académico pongan de manifiesto sus excelencias investigadoras? ¿O es que no les interesa, o no pueden, hacer que la actividad investigadora conste expresamente entre las obligaciones contractuales, porque los sueldos del profesorado habrían de ascender en ese caso por encima de lo que interesa, o puede, ofrecerse (aparte de que eso conllevaría una reducción de las cargas docentes por profesor, y por tanto se necesitarían más profesores para satisfacer la misma cantidad de docencia, so pena de reunir a los alumnos en grupos todavía más masificados o aplicar criterios de acceso a la Universidad más restrictivos para reducir el número de alumnos)? 
Seamos benevolentes al máximo, cándidos incluso, y preguntémonos: ¿será simplemente que el sistema español de Ciencia y Tecnología vigente es relativamente "joven" (al menos lo es la denominada Ley de la Ciencia, que data de 1986), y a la Universidad española, inmersa en dinámicas secularmente "espesas", de difícil cambio, no le ha dado tiempo a asimilarlo con tanta agilidad como lo ha hecho el CSIC, por ejemplo? En todo caso, ¿da esto pie o no para que algunos profesores funcionarios desaprensivos puedan obligar a "sus" becarios y contratados a investigar en aquello que a ellos más les interesa por razones que pueden ser meramente coyunturales, lo que al menos en el caso de los contratados postdoctorales con una experiencia investigadora más o menos dilatada, que llegan a un Departamento como profesores asistentes (asociados o ayudantes) con una línea ya establecida, puede resultar completamente absurdo, teniendo en cuenta que el contrato les obliga sólo a dar clase? Por otro lado, ¿cómo es posible que a la hora de la promoción apenas cuenten, si cuentan algo, el resto de nuestros resultados, los que no derivan de la actividad investigadora... ¡siendo la docencia lo único a que nos obliga el contrato (ya sea temporal o funcionarial)!? ¿Es porque hay colegas influyentes en el entorno de la ANEP, procedentes del CSIC (donde no hay obligaciones docentes), que asumen que el resto de los resultados no son cuantificables ni medibles? ¿Es que esa idea, parcialmente inexacta, como no dudo que se irá demostrando poco a poco, se ha extendido rápidamente y se asume como postulado casi dogmático? En todo caso, es verdaderamente singular todo esto. Que yo sepa, es una situación laboral única.

Quienes investigamos (con mayor o menor éxito, esa es otra cuestión) sabemos cuánto tiempo y energía demanda esta actividad. Sabemos que de la excelencia de nuestra investigación dependerá en parte el nivel de los contenidos que transmitamos al alumnado en clase y dependerá nuestra reputación como investigadores, medida entre otras cosas como complemento salarial (en forma de tramos de investigación). En este contexto, nada de extraño tiene que muchos de 
aquellos que más comprometidos se sienten con la investigación tiendan a dedicar poco tiempo a la concepción de una tarea docente dinámica, participativa, crítica, bien estructurada y que trascienda la mera exposición de unos contenidos, por puestos al día y conceptualmente excelentes que sean. En algunos casos se llega incluso a olvidar, o se actúa como si así ocurriera, que uno de los objetivos de la Universidad, puede que el principal, es que los alumnos salgan de ella sólidamente formados, desatendiéndose la preparación de las clases, las tutorías, etc. El tiempo tiene sus límites, y no nos debería extrañar una actitud tal en el contexto actual de proliferación de grupos con manifiesta escasez de profesores asistentes competentes, motivados y suficientemente remunerados y el concomitante exceso de cargas docentes, en un contexto en que la etiqueta de excelencia sólo depende de las publicaciones en revistas de impacto. No nos debería extrañar; lo cual no significa que sea justificable.

Esto, obviamente, es sólo un lado del espejo. Al otro lado, y de esto seguramente todos conocemos muchos casos, están aquellos que investigan (o, en ciertos casos, hacen que investigan) hasta conseguir un cierto rango, y a partir de ahí se limitan a dar sus clases automáticamente, siempre de acuerdo al mismo guión, y no se preocupan más de la labor investigadora. Lo que, aunque también injustificable, es asimismo perfectamente comprensible en el contexto actual en el que tanto se nos pide y tan poco se nos da. Es especialmente comprensible en aquellos profesores que no son vocacionales, sino que obtuvieron un contrato cuando acabaron la carrera y ahí siguen, como podrían estar picando toros en la Maestranza, tocando las castañuelas o aparcando coches en el Arenal (permítaseme la licencia, ahora que todavía estoy en Sevilla).

Creo que la comentada dicotomía docencia-salario frente a investigación-promoción, en la que cada término del binomio funciona con su dinámica particular (de ahí lo de "esquizofrenia"), lastra con una considerable ambigüedad al sistema universitario 
español y lo hace permeable a toda clase de triquiñuelas, de las que seguramente todos podemos relatar algunas (sufridas incluso en carne propia). Lamentablemente, la Universidad española (y seguramente debería decir la Universidad en general; Stanley \& Higley, 2000) no ha conseguido todavía resolver adecuadamente el dilema, y las consecuencias son, desde mi punto de vista, muy negativas tanto para la institución en general como para el alumnado en particular.

En mi modesta opinión, contrastada con la de numerosos colegas, la actividad investigadora debería estar mejor reglada y tenerse en cuenta a la hora de las contrataciones. Por contra, y he aquí otra de las cuestiones clave, todavía no se han establecido unos criterios claros, serios, relativamente objetivos y fácilmente aplicables de evaluación de la calidad docente, cuyo progreso debería poderse medir de alguna forma realista y tenerse en cuenta a la hora de la promoción profesional (recuérdese que un buen profesor no es simplemente aquel que más tiempo dedica a las tareas docentes, como se quiere sobreentender muchas veces con cierta, o mucha, malicia: se trata de dedicar mayor intensidad en la dirección correcta, cuyo corolario inmediato es que no se es necesariamente mejor docente por haber dado clases muchos años, aunque pueda existir algún tipo de correlación entre ambos factores hablando en términos generales). No digo que no se intenten establecer dichos criterios; de hecho ha habido algunos avances significativos en este aspecto en distintas Universidades españolas en los últimos años. Pero de momento hay que reconocer que esto está lejos de haberse conseguido todavía de una manera relativamente objetiva, realista y eficaz. Las encuestas a los alumnos son necesarias, pero no suficientes. En algunas ocasiones las preguntas que se les hacen son confusas o están sesgadas, lo que invalida parcial o totalmente los resultados (puedo dar datos muy concretos, si a alguien le interesan).

En mi opinión, debería tenderse a la creación de un organismo riguroso e independiente, al estilo de la ANEP, o que fuera parte de ésta misma agencia, cuyos 
juicios sobre la calidad docente (y sobre la actividad divulgadora) fueran aplicables tanto a los profesores numerarios como a los no numerarios, y tuviera consecuencias sobre ambos colectivos (de acuerdo con José L. Marín, com. pers., en el Reino Unido se está experimentando algo semejante; véase http://www.ilt.ac.uk). ¿Qué sentido tiene que docencia y divulgación sean evaluadas sólo por las propias Universidades o por empresas que éstas contratan (que tanto da), cuando todos sabemos los intereses creados que suelen subyacer? Eso puede devenir ridículo y hasta bochornoso, en ciertas instancias. Las Universidades pueden emitir juicios sobre determinados aspectos formales (sobre si se cumplen los horarios, el programa, etc.), pero nunca sobre cuestiones de fondo, que en definitiva son las que trascienden y marcan las diferencias. Estimados colegas funcionarios, os animo a que me repliquéis, porque puedo estar dejando de lado factores importantes, quizá fundamentales, en mi análisis.

Algunos quizá me diréis, con razón, que los méritos docentes son mucho más difíciles de evaluar que los investigadores, puesto que no existe una escala de comparación como es el índice de citas científicas. Naturalmente. Precisamente por eso, y con objeto de evitar arbitrariedades y trapacerías (Vázquez-Vaamonde, 1997), deberíamos tratar de trabajar seriamente en el establecimiento de unos criterios lo más objetivos y justos que fuera posible. ¡Claro que se puede! ¿No se va a poder? Pero hay que querer (y eso, por desgracia, ya no estoy tan convencido de que ocurra). Yo soy biólogo de campo, y nuestro colectivo recibió durante décadas fuertes críticas por parte de amplios sectores de los biólogos moleculares porque no éramos capaces, como ellos, de formular nuestras hipótesis y traducir nuestros resultados a expresiones matemáticas simples y ampliamente generalizables. Muchos de ellos pensaban que no era posible y, durante un tiempo, trataron con cierto desprecio a la biología de campo, como si fuera ciencia de segunda (de lo que, por cierto, siguen quedando secuelas). Hasta que se aplicaron las herramientas estadísticas adecuadas, a base de mucho esfuerzo y trabajo, y se comprendió que los fenómenos que ocurren 
a nivel de sistemas de organismos deben expresarse en función de probabilidades. $\mathrm{O}$ sea, a otro nivel, otro método. Pues en esto, igual. En la lista de distribución de la AACTE ya he lanzado varias veces la idea de formar un grupo que trabaje, al menos al nivel de borrador, sobre propuestas de criterios de evaluación de la actividad docente. Es posible, y hasta probable, que se hayan instituido algunos grupos de tal naturaleza en alguna Facultad de Ciencias de la Educación. ¿Es así? ¿Hay alguien ahí que lo sepa? ¿O que comparta esta inquietud, que esté dispuesto a involucrarse? ¿Al menos para discutir sobre ello?

Como resultado de la mencionada dicotomía de criterios, en las áreas de Ciencias son relativamente escasos los profesores que investigan con seriedad y a la vez se sienten verdaderamente comprometidos con la calidad académica, técnica e intelectual de la docencia que imparten. Algunos nos bandeamos por donde podemos y otros, hay que reconocerlo, muestran poco interés en que las cosas mejoren. Dándole la vuelta al asunto, en realidad deberíamos preguntarnos si no es demasiado pedir a los profesores que den tantas clases como deben dar, que las den bien (poniéndose constantemente al día) y motiven a los estudiantes, que divulguen los conocimientos y que además produzcan buena investigación. En mi opinión, puede llegar a ser excesivo. En realidad, la distancia que hay entre lo que debería exigírsele a un profesor y lo que se le paga es desmedida, en muchos casos incluso escandalosa.

¿Cómo podría resolverse toda esta situación tan compleja? En primer lugar, reconociéndola. No sirve de mucho que en ciertos círculos se hable reiteradamente del tema si después, en el quehacer académico diario, lo soslayamos más o menos conscientemente en función de otros intereses (que no digo que no haya algunos que no sean lícitos y hasta importantes; pero, en todo caso, parecen secundarios respecto del objetivo fundamental). Lo que podría denominarse la "versión crítica de la versión oficial", que puede encontrarse en el "informe Bricall" o Informe Universidad 2000 (http:/ / www.crue.upm.es), es interesante y refleja, además, la loable intención 
de, al menos, plantearse algunas de estas cuestiones. Pero, como ha sido comentado ya en numerosos documentos (véase recopilación en http://www.soc.um.es/gi/gqo/ y vínculos), las soluciones que bosqueja son demasiado "descafeinadas" (en parte porque no ataca de frente, sino de soslayo, algunos problemas evidentes, entre ellos el que se comenta aquí), y todo el informe es excesivamente autocomplaciente. Muchos nos tememos que no vaya a servir para mucho, porque es realmente difícil ser a la vez juez y parte. Quizá hubiera sido más útil y válido un informe realizado por una mayoría de observadores externos a la Universidad, o pertenecientes a otras Universidades europeas.

En segundo lugar, motivando a los profesores con sueldos acordes con su función y no saturándoles con cargas docentes tales que desvíen excesivamente su atención de la preparación adecuada de las clases, de sus proyectos de investigación y de la importante faceta de la transmisión de la información al tejido social (que he dejado un poco de lado a lo largo del texto, lo reconozco). Asunto el del sueldo, todos lo comprendemos, difícil de abordar, como todos aquellos a los que subyace una base económica, y que requeriría un buen nivel de consenso porque, me temo, exigiría introducir determinados cambios en la LRU (para que no quedara en un mero parche).

$\mathrm{Y}$ en tercer lugar, ejerciendo un control riguroso e imparcial sobre el resultado global de la actividad de los todos los profesores, lo que hoy día es poco menos que una utopía. Esto último es especialmente cierto (y espinoso) para el caso de los numerarios, que de hecho pueden hacer o deshacer casi a su antojo (jeso no quiere decir que todos lo hagan!), invocando a veces a la "libertad de cátedra" de manera harto arbitraria. Todos conocemos casos, algunos bien cercanos, de quienes abusan de su posición de privilegio en su propio beneficio personal, porque saben que en determinados aspectos nadie va a pedirles cuentas. Difícilmente podremos mejorar como docentes, y por lo tanto mitigar la frustración de nuestros estudiantes, si no nos 
planteamos el problema en toda su dimensión, sea su solución fácil o difícil, haya o no que poner el dedo en llagas sangrantes.

No pocos colegas piensan que las soluciones no pueden venir del seno de la comunidad universitaria, ya que la dinámica gremial imperante en la mayoría de los Departamentos, Facultades y Universidades conduce a que no se pueda esperar del grueso de los profesores más que complicidad con los intereses particulares de esos Departamentos, Facultades y Universidades, independientemente de los intereses generales de la Universidad como institución al servicio del ciudadano. Probablemente tengan gran parte de razón quienes esto dicen. De hecho, las propuestas que hago aquí tienen poco de original, y corren de boca en boca por entre aquellas más inquietas. Pero se argumenta que hay demasiados intereses creados, demasiado favor debido, demasiada corrupción y cinismo asumidos con toda naturalidad como para que propuestas de este tipo lleguen a plantearse desde dentro ni siquiera como alternativas dignas de estudio. Sin embargo, yo me resisto a cruzarme de brazos. Si la respuesta no viene de nosotros, ¿de dónde va a venir, teniendo en cuenta la imagen que el ciudadano medio tiene de la Universidad?

Debemos espabilarnos, porque la que le puede venir encima a nuestra pobre Universidad como sigamos por estos derroteros, en el contexto del avance científicotécnico tan formidable al que estamos asistiendo (y al que el CSIC, con todos sus defectos, se ha sabido integrar con gran eficacia), puede ser tremenda. Debemos, en primer lugar, cumplir lo mejor que podamos nuestro papel de enseñantes e investigadores, formadores de profesionales y divulgadores. $\mathrm{Y}$ en segundo lugar debemos dialogar sobre estas cuestiones, por espinosas que sean, participando en foros como éste (por más que nos confundamos en algún planteamiento; "el que tiene boca se equivoca", pero el que la tiene cerrada es como si no la tuviera), organizando mesas redondas en torno al tema si es preciso. Debemos movilizarnos, de la manera más conveniente. Entre otras cosas, para intentar que en un plazo razonable se 
contemple la posibilidad de la evaluación rigurosa e independiente de la actividad docente de todos los profesores, y que los resultados se tengan en cuenta a la hora de la promoción. En otras palabras, para complementar los análisis exhaustivos pero menos comprometidos, más complacientes, de los sectores más oficiales con otros análisis más incisivos y probablemente más certeros en al menos algún planteamiento, en particular sobre asuntos que cabría denominar "de a pie". Hay que incentivar a quien trata de hacer bien su tarea y exigir explicaciones a quien, reiteradamente, incumple con una responsabilidad tan delicada como la formación superior de nuestra juventud (sea o no sea funcionario).

Comprendo que la cuestión de la evaluación rigurosa de la actividad docente del personal funcionario es asunto muy delicado, y que las susceptibilidades se pueden herir con facilidad. Es posible que hasta sea incompatible con el funcionariado, tal como ahora se contempla. Pero antes o después, si España desea tener un sistema universitario competente en nuestro entorno cultural y que deje un legado profesional, intelectual y moral de auténtico calado en la sociedad, deberá abordarse de una forma o de otra, por utópico que parezca ahora mismo. Mi impresión personal es que muchos funcionarios no tendrían ningún inconveniente en someterse a una evaluación rigurosa e independiente (eso no significa exigente en exceso, sino seria) que pudiera premiar económicamente sus progresos docentes o, alternativamente, sancionar su eventual inoperancia.

Los no funcionarios, o al menos aquellos que (supuestamente) hemos sido contratados en función de nuestros méritos, estamos mayoritariamente dispuestos, siempre y cuando se nos dote de unas condiciones de trabajo tales que nos permitan alcanzar un cierto nivel de competencia en lo docente y en lo investigador y no se nos bloquee con pretextos dudosos, como ocurre en algunos casos (de cuyo nombre no quiero acordarme). Si esto fuera algún día posible, aquellos que se parapetan tras su condición de funcionarios y cumplen de manera más o menos rutinaria quedarían 
inmediatamente en evidencia. Sería sin duda duro y difícil; pero sería también un gran paso hacia la consecución de una Universidad realmente moderna, excelente y democrática. Lo contrario no conduciría sino a seguir haciendo aumentar la madeja de los intereses oscuros y favorecer la dinámica por la cual las Universidades, independientemente de su edad y de su localización geográfica, van siendo carcomidas poco a poco por la rémora interna de profesorados en parte caducos y más preocupados de sí mismos que de cumplir la misión de servicio público que tienen encomendada.

\section{Agradecimiento}

Este texto ha sido enviado a la lista de distribución de la AACTE y sometido a las críticas de sus miembros (lo cual no quiere decir que refleje una postura común). Agradezco especialmente su colaboración a Juan Gallardo Lancho y a Julio Gutiérrez Muñoz, así como comentarios de José Luis Marín y Angel Cebolla. A Julio Gutiérrez Muñoz le agradezco la invitación para que fuera publicado en la revista virtual Vivat Academia. En buena parte, este artículo es el resultado de intercambios de opinión con numerosos colegas, entre ellos Eduardo Aguilera, Xim Cerdá, Pablo Ferreras y Pedro Jordano, y con mis alumnos de la UPO (a quienes debo gran parte de la inspiración que me haya podido acompañar estos dos últimos años). Agradezco también las sugerencias y comentarios críticos de Mario Díaz, mi hermano Carlos Yela y mi mujer, Charo Berzosa.

\section{Bibliografía}

CAMÍ, J. (1997).- Impactolatría: diagnóstico y tratamiento. Medicina Clínica, 109: 515-524.

CARRASCAL, L. M. (1997).- La cita bibliográfica como medida de "utilidad científica". Etologuía, 15: 17-30. 
ORTEGA Y GASSET, J. (1930).- Misión de la Universidad. Ediciones de la Revista de Occidente. Madrid.

RAMÓN Y CAJAL, S. (1919).- Caciquismo universitario. El Siglo Médico.

STANLEY, D. W. \& HIGLEY, L. G. (2000).- What are graduate students preparing to do? American Entomologist, 46 (2): 73-74.

VÁZQUEZ-VAAMONDE, A. J. (1997).- Donde no hay medida, no hay ciencia: sólo arbitrariedad. Boletín de la Asociación de Personal Investigador del Consejo Superior de Investigaciones Científicas, 9: 14-18.

YELA, C. (en prensa).- El papel de la psicología académica: el debate educación profesionalización. El papel de la Psicología académica: una perspectiva crítica. Universidad Complutense de Madrid. Madrid.

YELA, J. L. (2000).- Formación especializada en ecología y educación medioambiental: conceptos fundamentales y aplicación al voluntariado. Formación en voluntariado social (ed. Diputación Provincial de Sevilla), pp. 89-111. Universidad Pablo de Olavide. Sevilla.

YELA, J. L. (en prensa a).- Entre dos aguas (II). Tendiendo puentes (sobre corrientes turbulentas): de la evolución como proceso a la nomenclatura como herramienta.Boletín de la Sociedad Entomológica Aragonesa.

YELA, J. L. (en prensa b).- La Entomología ibérica del tercer milenio: razones para un cierto optimismo (o "las cosas no son como son, sino como hacemos que sean").Boletín de la Sociedad Entomológica Aragonesa. 